\title{
Small-area variation in screening for cancer, glucose and cholesterol in Ontario: a cross-sectional study
}

\author{
Kimberly A. Fernandes MSc, Rinku Sutradhar PhD, Cornelia M. Borkhoff PhD, Nancy Baxter MD PhD, \\ Aisha Lofters MD PhD, Linda Rabeneck MD MPH, Jill Tinmouth MD PhD, Lawrence Paszat MD MS; \\ on behalf of the investigators of the Ontario Cancer Screening Research Network
}

\section{Abstract}

Background: Screening for cervical, breast and colon cancers, and elevations of cholesterol and glucose, reduces premature causespecific mortality from these cancers and circulatory diseases. Despite primary care reforms and incentives, and promotion of cancer-screening programs among individuals, participation is suboptimal. We aimed to examine participation as of Dec. 31 , 2011, by factors of deprivation, demographics and primary care at the small-area level.

Methods: From health care administrative databases, we identified people eligible for each screening test, and their participation, in each dissemination area (referred to as small areas, $n=18950$ ) in Ontario. We calculated rates for each test among small areas (overall and stratified by demographic, socioeconomic and primary care descriptors) and stratified by sex for all tests combined. We loaded all data into a geographic information system. Funnel plots were generated showing the percentage of eligible people who completed screening for all tests by small area, stratified by sex. Overall and stratified screening prevalence ratios were calculated among small areas.

Results: Among small areas, the mean and SD for participation in all tests combined was 31.6\% (SD $11.0 \%$ ) for women and $41.2 \%$ (SD 12.0\%) for men. Screening prevalence among small areas, for each test and for all tests combined, overall and stratified by sex, declined with decreasing percentage with high school completion, decreasing socioeconomic quintile, and decreasing percentage with an identifiable primary care physician.

Interpretation: Our results show that the rate of participation in all eligible screening tests among small areas is much lower than the rate of participation in any one particular test. This finding has implications for the design and implementation of strategies to improve rates of screening.

creening for cervical, breast and colon cancers, and
elevations of cholesterol and glucose, reduces pre-
mature cause-specific mortality from these cancers and
circulatory diseases. ${ }^{1-5}$ Uptake of these tests in Ontario is not
optimal, ${ }^{6}$ despite efforts aimed at "average" individuals,
including promotion of cancer-screening programs in English
and French, ${ }^{7}$ financial incentives to primary care physicians
for cancer screening, ${ }^{8}$ increasing numbers of physicians, the
introduction of patient enrolment models and other
enhanced practice models for primary care. ${ }^{9}$ There is no
coordination or integration of participation across these cancer
screening tests, or with glucose and cholesterol screening.
Using small area-based methods, ${ }^{10-13}$ we have previously
shown the association of small-area rates of participation
with ecologic measures of income and immigration status as
of Dec. $31,2009 .{ }^{10}$
To facilitate small area-level, community-based and pri-
mary care-based strategies to improve participation, our goal
in the present work was to examine participation as of Dec.
31,2011 , by additional factors of deprivation, demographics and primary care. Second, we aimed to analyze participation at the level of eligible individuals to assess whether area-level results were consistent with individual-level results. Third, we wished to show how these enhanced data would facilitate the planning of appropriate strategies to improve participation among demographically characterized small areas.

\section{Methods}

We obtained approval from the Research Ethics Board at Sunnybrook Health Sciences Centre in Toronto, Ontario, and conducted the work at the Institute for Clinical Evaluative Sciences.

Competing interests: None declared.

This article has been peer reviewed.

Correspondence to: Lawrence Paszat, lawrence.paszat@ices.on.ca CMAJ Open 2015. DOI:10.9778/cmajo.20140069 


\section{Study design}

This is a cross-sectional study of small-area variation in screening participation in Ontario.

\section{Study population}

Potential eligible people for these types of screening were identified from the Ontario Health Insurance Plan (OHIP) Registered Persons Database by age and sex, and linked using unique encoded identifiers to health service databases, disease registries, the Citizenship and Immigration Canada database, and ecologic linkage to census variables via postal codes. People affected by colon, breast or cervix cancer, diabetes mellitus or myocardial infarction were identified in the Ontario Cancer Registry, the Ontario Diabetes Database and the Ontario Myocardial Infarction Database, and excluded from eligibility for the corresponding tests, and also those with a billing claim for hysterectomy, mastectomy or major colon resection. These databases are complete for all permanent residents of Ontario.

Residence location was assigned by postal code conversion to census dissemination areas (referred to as small area, $n=$ 18 950). The numeric code for the dissemination area remains the identifier for each small area.

Eligible permanent residents and refugees in Ontario (without exclusions based on prior diagnoses or organ resections) are insured for screening tests, but each must find a physician on arrival in Ontario, after moving within Ontario, or after their physician moves away or retires. These are not barriers for most middle- and upper-income people, but are barriers in low-income areas. ${ }^{10,11,14-25}$

\section{Measurement and outcomes}

\section{Screening eligibility and participation}

Table $1^{26-30}$ describes data sources for all tests, eligibility and recommended screening interval before Dec. 31, 2011, for which participation was identified. In Ontario, cervical screening is recommended up to age 69 years, breast and colon screening from age 50 to 74 years, glucose screening from age 40 to 74 years, and cholesterol screening among men beginning at age 40 years and among women at 50 years.

Participation in screening was measured using fee codes in the OHIP database, and inclusion in the CytoBase or Ontario Breast Screening Program databases. Uptake of each test was measured as having received at least 1 screening test during the look-back window before Dec. 31, 2011.

\section{Factors of demography, deprivation, barriers and primary care}

From physician billing claims, we determined the following for each small area: the univariate distribution of primary care visits during 2010 and 2011, percentage of screen-eligible people enrolled with a patient enrolment model practice, and percentage of screen-eligible people not enrolled but for whom a primary care physician is identifiable who does not have a patient enrolment model practice (most primary care visits during 2010 and 2011). Among physicians, we identified physician age, sex, years since graduation, country of medical graduation, and whether the physician has a patient enrolment model practice from the corporate providers database that is maintained by the institute.

Table 1: Inclusion and exclusion criteria for identification of people eligible for screening

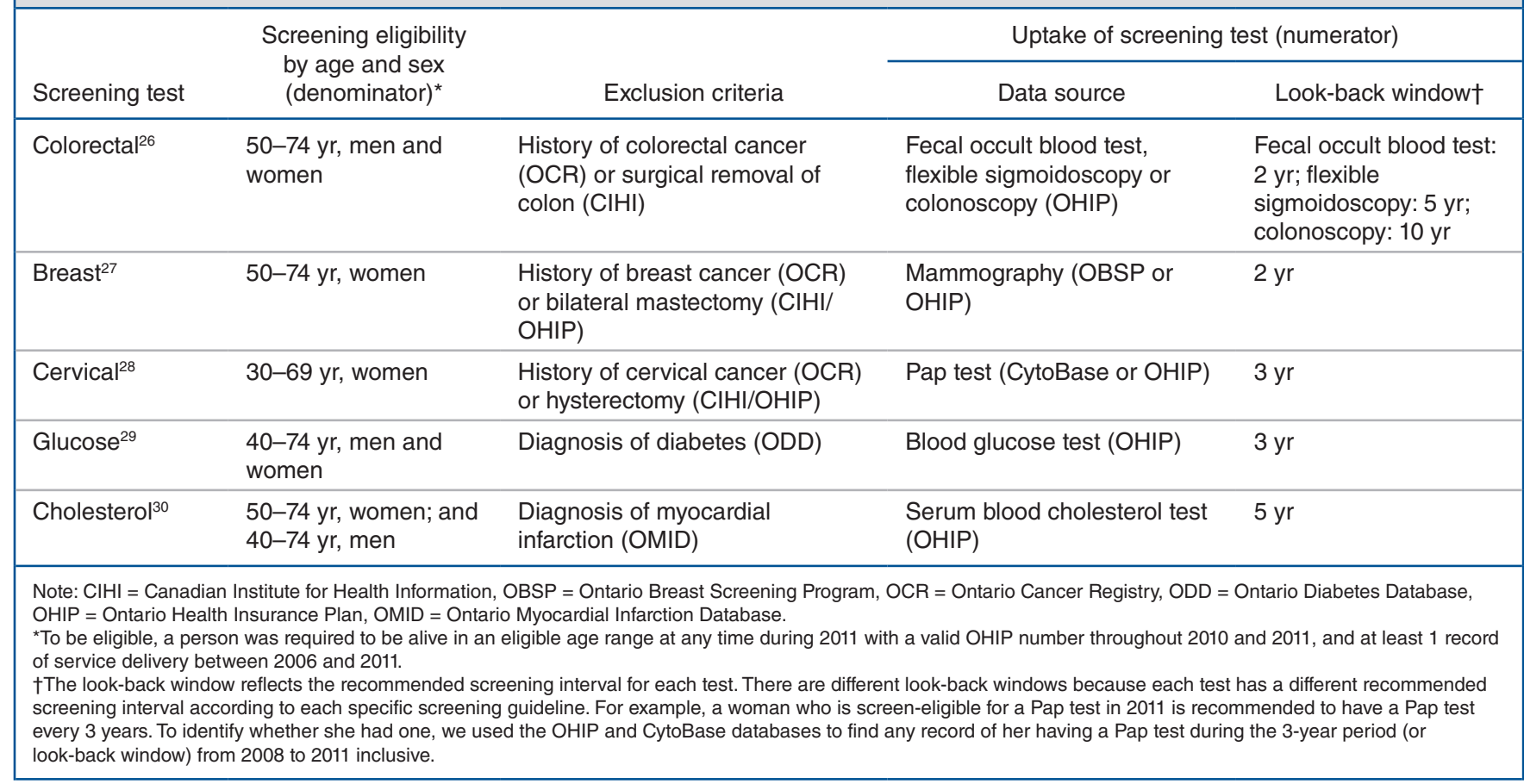


From information collected at the 2006 census, each small area was described by rural versus urban, quintiles of urban median household income, percentage without high school completion, and percentage among whom neither official language is spoken at home. The proportion of immigrants among eligible people was determined for each small area, by time since arrival.

\section{Analysis}

Continuous variables were categorized by small area based on distributional cut-offs (those in the bottom 10th percentile were categorized as high deprivation, and those in the top 10th percentile were categorized as low deprivation).

Small-area participation rates and demographic, deprivation, barrier and primary care factors were input to the geographic information system of Cancer Care Ontario. ${ }^{31}$ Rates of eligible people being up to date on all 5 tests for women and all 3 tests for men in small areas in Ontario were computed. The average rates for all tests combined among eligible people, over all small areas, were plotted along with the corresponding $95 \%$ and $99 \%$ control limits, which were generated using the asymptotic normal approximation set at 2 and 3 standard deviations, respectively. These control limits represent the expected bound around the average rate for varying screeneligible population sizes. The observed rate for each small region is then overlaid on the plot at their actual population size. Small areas with rates that fall outside of the control limits are significantly different from what would be expected. ${ }^{12,13}$

We calculated screening prevalence as the percentage of eligible people having each test per small area; among the subsets of women aged 50-69 years and men aged 50-74 years, the prevalence of having all eligible tests (during these age groups, 5 tests for women, and 3 tests for men), each individual test, and at least one of any test, were also calculated per small area and summarized. Screening prevalence is stratified by deprivation and barrier variables, and number of primary care visits per eligible person per small area. ${ }^{12,13}$

\section{Individual-level description and analysis}

In Appendix 1 (available at www.cmajopen.ca/content/3/4/ E373/suppl/DC1), we present analysis and results using the individual eligible person as the unit of analysis to assess whether area-level and individual-level results were generally consistent. Complete case analyses were carried out owing to the low percentage of people $(<1.0 \%)$ with incomplete data among the eligible people. Because the outcome was fundamentally collected at the individual level, and because it is not appropriate to analyze grouped binary data with small denominators, as if it were count data following a Poisson distribution, we proceeded with an individual analysis under binomial assumptions. ${ }^{32-35}$

\section{Results}

\section{Results from small areas}

Of the 3843422 women (aged 30-74 yr) and 2853590 men (aged 40-74 yr) who were age-eligible for any of the screening tests in 2011, 38176 women and 2204 men met the exclusion criteria (outlined in Table 1) for all screening tests, resulting in 3805246 women and 2851386 men comprising the study cohort.

\section{Table 2: Descriptive statistics of 18950 small areas in Ontario containing men and women eligible for colorectal, breast, cervical, glucose or cholesterol screening tests}

Characteristic Value

Completed high school, \%

Mean (SD) $80.68(11.54)$

Bottom 10th percentile $\quad 0-65$

Median (IQR) 82 (74-89)

Top 10th percentile $\quad 94-100$

Home language is English or French, \%

Mean (SD) 98.13 (3.71)

Bottom 10th percentile 45-94

Median (IQR) $100(98-100)$

Top 10th percentile 100-100

Immigrants arriving in Canada within last ..., \%

0-8 yr (recent)

Mean (SD) 3.85 (5.16)

Bottom 10th percentile $\quad 0-0.19$

Median (IQR) $2(1-5)$

Top 10th percentile 11-52

9-16 yr

Mean (SD)

$3.87(4.80)$

Bottom 10th percentile $\quad 0-0.18$

Median (IQR) $2(1-6)$

Top 10th percentile 11-29

17-27 yr (distant)

Mean (SD)

$4.29(4.62)$

Bottom 10th percentile $\quad 0-0.32$

Median (IQR) 2 (1-6)

Top 10th percentile 12-29

Nonimmigrants, \%

Mean (SD)

$87.99(13.53)$

Bottom 10th percentile

20-66

Median (IQR)

$94(82-98)$

Top 10th percentile

99-100

Income quintile with mean income per quintile, \$, no. (\%)

Q1 (44 722) 2964 (15.6)

Q2 (62 080) $3380(17.8)$

Q3 (74 910) 3198 (16.9)

Q4 (88 465) $3254(17.2)$

Q5 (129 777) $3430(18.1)$

Rural $2672(14.1)$

Note: IQR = interquartile range 
Table 3: Descriptive statistics of 18950 small areas containing men and women eligible for colorectal, breast, cervical, glucose or cholesterol screening tests

\begin{tabular}{|c|c|c|c|c|c|c|c|c|}
\hline \multirow[b]{2}{*}{ Characteristic } & \multicolumn{5}{|c|}{ Women } & \multicolumn{3}{|c|}{ Men } \\
\hline & Colorectal & Breast & Cervical & Glucose & Cholesterol & Colorectal & Glucose & Cholesterol \\
\hline Screen-eligible people, no. & 1919046 & 1890329 & 3199197 & 2598759 & 1935221 & 1819904 & 2410743 & 2782569 \\
\hline Small areas with screen-eligible people, no. & 18944 & 18944 & 18947 & 18946 & 18943 & 18939 & 18948 & 18950 \\
\hline \multicolumn{9}{|c|}{ Characteristics of screen-eligible people, summarized over small areas } \\
\hline \multicolumn{9}{|l|}{ Screen-eligible people, no. } \\
\hline Mean (SD) & $101(78)$ & $100(77)$ & $169(193)$ & $137(122)$ & 102(79) & $96(73)$ & $127.23(114)$ & $147(133)$ \\
\hline Bottom 10th percentile & $1-51$ & $1-50$ & $1-86$ & $1-71$ & $1-51$ & $1-50$ & $1-67$ & $1-78$ \\
\hline Median (IQR) & $85(66-113)$ & $84(65-111)$ & $132(106-175)$ & $114(90-149)$ & $86(67-114)$ & $82(64-108)$ & $106(85-139)$ & $121(98-159)$ \\
\hline Top 10th percentile & $160-3407$ & 158-3 355 & $262-10811$ & 214-6 426 & $162-3439$ & $151-3501$ & 196-6 197 & $227-7131$ \\
\hline \multicolumn{9}{|l|}{ Median age, yr } \\
\hline Mean (SD) & $59(2)$ & $59.36(2.13)$ & $48.74(3.40)$ & $53.48(2.88)$ & $59.44(2.14)$ & $59.24(2.09)$ & $52.98(2.70)$ & $53.92(2.75)$ \\
\hline Bottom 10th percentile & $50-57$ & $50-57$ & $31-45$ & $40-50$ & $50-57$ & $50-57$ & $40-50$ & $40-51$ \\
\hline Median (IQR) & $59(58-61)$ & $59(58-61)$ & $49(47-51)$ & $53(52-55)$ & $59(58-61)$ & $59(58-61)$ & $59(58-61)$ & $53(51-55)$ \\
\hline Top 10th percentile & 62-75 & 62-75 & 53-68 & $57-75$ & 62-75 & 62-75 & 56-75 & $57-73$ \\
\hline \multicolumn{9}{|c|}{ Median visits to primary care provider within $2 \mathrm{yr}$, no. } \\
\hline Mean (SD) & $6.68(2.07)$ & $6.65(2.07)$ & $5.57(1.71)$ & $5.81(1.72)$ & $6.68(2.06)$ & $5.15(1.69)$ & $3.89(1.29)$ & $4.27(1.42)$ \\
\hline Bottom 10th percentile & $0-4$ & $0-4$ & $0-4$ & $0-4$ & $0-4$ & $0-3$ & $0-2$ & $0-3$ \\
\hline Median (IQR) & $6(5-8)$ & $6(5-8)$ & $5(4-7)$ & $6(5-7)$ & $6(5-8)$ & $5(4-6)$ & $4(3-5)$ & $4(3-5)$ \\
\hline Top 10th percentile & $9-68$ & $9-68$ & $8-19$ & $8-23$ & $62-68$ & $7-26$ & $6-26$ & $6-25$ \\
\hline \multicolumn{9}{|c|}{ People rostered (either virtually or via a patient enrolment model) to a primary care provider, \% } \\
\hline Mean (SD) & $96.35(4.37)$ & $96.32(4.40)$ & $95.47(4.39)$ & $95.8(4.32)$ & $96.37(4.36)$ & $93.6(5.51)$ & $91.3(5.97)$ & $92.19(5.53)$ \\
\hline Bottom 10th percentile & $0-93$ & $0-93$ & $0-92$ & $0-92$ & $0-93$ & $0-88$ & $0-85$ & $0-87$ \\
\hline Median (IQR) & $97(95-99)$ & $97(95-99)$ & $96(94-98)$ & $97(95-98)$ & $97(95-99)$ & $95(92-97)$ & $93(89-95)$ & $93(90-95)$ \\
\hline Top 10th percentile & $100-100$ & 100-100 & $99-100$ & $99-100$ & 100-100 & 98-100 & $97-100$ & $97-100$ \\
\hline \multicolumn{9}{|c|}{ People rostered via a patient enrolment model to a primary care provider, \% } \\
\hline Mean (SD) & $85.9(8.89)$ & $85.9(8.92)$ & $84.52(8.53)$ & $85.07(8.64)$ & $86(8.86)$ & $81.06(10.07)$ & $77.8(10.33)$ & $79.0(9.90)$ \\
\hline Bottom 10th percentile & $0-76$ & $0-76$ & $0-75$ & $0-76$ & $0-76$ & $0-69$ & $0-65$ & $0-67$ \\
\hline Median (IQR) & $87(82-92)$ & $87(82-92)$ & $86(81-90)$ & $86(81-91)$ & $87(82-92)$ & $83(76-88)$ & $79(72-85)$ & $80(74-86)$ \\
\hline Top 10th percentile & $95-100$ & $95-100$ & $93-100$ & 94-100 & $95-100$ & $92-100$ & $89-100$ & $90-100$ \\
\hline \multicolumn{9}{|c|}{ Characteristics of screen-eligible people's primary care provider, summarized over small areas } \\
\hline \multicolumn{9}{|l|}{ Median age of primary care provider, yr } \\
\hline Mean (SD) & $52.86(2.85)$ & $52.86(2.86)$ & $51.66(2.40)$ & $52.30(2.54)$ & $52.86(2.84)$ & $53.61(2.95)$ & $52.97(2.67)$ & $53.01(2.63)$ \\
\hline Bottom 10th percentile & $31-49$ & 29-49 & $31-49$ & $31-49$ & $31-49$ & $33-50$ & $33-50$ & $35-50$ \\
\hline Median (IQR) & $53(51-55)$ & $53(51-53)$ & $52(52-53)$ & $52(51-54)$ & $53(51-55)$ & $54(52-56)$ & $53(51-55)$ & $53(51-55)$ \\
\hline Top 10th percentile & $56-68$ & $56-68$ & $55-68$ & $55-70$ & $56-68$ & $57-80$ & $56-80$ & $56-80$ \\
\hline \multicolumn{9}{|c|}{ Among eligible people with an identifiable primary care provider } \\
\hline \multicolumn{9}{|l|}{ Female primary care provider, $\%$} \\
\hline Mean (SD) & $39.84(11.93)$ & $39.79(11.98)$ & $43.31(11.55)$ & $41.89(11.79)$ & $39.87(11.91)$ & $23.74(8.46)$ & $25.28(8.32)$ & $25.42(8.06)$ \\
\hline Bottom 10th percentile & $0-25$ & $0-25$ & $0-29$ & $0-27$ & $0-25$ & $0-14$ & 0-15 & $0-16$ \\
\hline Median (IQR) & $39(31-48)$ & $39(31-48)$ & $43(35-52)$ & $41(33-50)$ & $39(34-48)$ & $23(18-29)$ & $25(20-31)$ & $25(20-31)$ \\
\hline Top 10th percentile & $56-100$ & $56-100$ & $59-100$ & $57-100$ & $56-100$ & $35-100$ & $36-100$ & $36-100$ \\
\hline \multicolumn{9}{|l|}{ Canadian medical graduates, median (IQR), \% } \\
\hline Mean (SD) & $80.51(11.19)$ & $80.49(11.20)$ & $80.36(10.57)$ & $80.76(10.62)$ & $80.54(11.15)$ & $80.58(11.30)$ & $80.66(10.86)$ & $80.49(10.74)$ \\
\hline 0-10th percentile & $0-66$ & $0-66$ & $0-66$ & $0-67$ & $0-66$ & $0-65$ & $0-66$ & $0-66$ \\
\hline Median (IQR) & $81(73-89)$ & $81(73-89)$ & $81(73-89)$ & $81(74-89)$ & $81(73-89)$ & $81(73-89)$ & $81(74-89)$ & $81(74-89)$ \\
\hline Top 10th percentile & $94-100$ & $94-100$ & $93-100$ & $94-100$ & $94-100$ & $94-100$ & $94-100$ & $93-100$ \\
\hline \multicolumn{9}{|l|}{ In patient enrolment model, \% } \\
\hline Mean (SD) & $93.77(5.28)$ & $93.78(5.29)$ & $93.69(4.53)$ & $93.76(4.75)$ & $93.78(5.22)$ & $92.60(5.73)$ & $92.28(5.47)$ & $92.31(5.25)$ \\
\hline Bottom 10th percentile & $0-88$ & $0-88$ & $0-89$ & $0-88$ & $0-88$ & $0-86$ & $0-86$ & $0-86$ \\
\hline Median (IQR) & $94(91-97)$ & $95(91-97)$ & $94(91-97)$ & $95(91-97)$ & $93(90-97)$ & $93(90-97)$ & $93(89-96)$ & $93(89-96)$ \\
\hline Top 10th percentile & $100-100$ & $100-100$ & $99-100$ & $99-100$ & $100-100$ & $100-100$ & $98-100$ & $98-100$ \\
\hline \multicolumn{9}{|l|}{ Median years since graduation } \\
\hline Mean (SD) & 27.25 (2.98) & $27.24(2.99)$ & $26.03(2.45)$ & $26.66(2.63)$ & $27.24(2.97)$ & $28.00(3.11)$ & $27.33(2.79)$ & $27.39(2.74)$ \\
\hline Bottom 10th percentile & $5-24$ & $3-24$ & $3-23$ & $5-24$ & $5-24$ & $3-24$ & $5-24$ & $7-24$ \\
\hline Median (IQR) & $27(25-29)$ & $27(25-29)$ & $26(25-28)$ & $27(25-28)$ & $27(25-29)$ & $28(26-30)$ & $28(26-29)$ & $27(25-28)$ \\
\hline Top 10th percentile & $31-44$ & $31-44$ & $29-42$ & $30-43$ & $31-44$ & $32-49$ & $31-49$ & $31-49$ \\
\hline
\end{tabular}


Table 2 summarizes the distribution of deprivation factors and barriers to screening among 18950 small areas in Ontario. Levels of factors in the bottom 10th percentiles of small areas indicate a range of challenges to overcome for improved screening participation in comparison to other small areas. These include high school completion rates less than $66 \%$ and rates of English or French spoken at home less than $95 \%$.

Table 3 summarizes people eligible for each test per small area, stratified by sex, the variability in the number of visits to a primary care physician within 24 months, and physician characteristics. We identified a physician for $95 \%$ of women and $91 \%$ of men, and the physician's practice was a patient enrolment model for $84 \%$ of women and $77 \%$ of men. Compared with women, screen-eligible men were more likely to have an older and/or male physician, and fewer visits. Ten percent of small areas had less than $67 \%$ of screen-eligible people with a Canadian graduate as their physician.

Figure 1 provides 2 illustrations of information that can be easily observed from the geographic information system for any small area in Ontario for any screening test, and all tests combined, stratified by sex. The roads transecting the neighbourhood, the participation rate among eligible people, income quintile, home language, recency of immigration, high school completion, and information about primary care as delivered and received by screen-eligible people in the small area can be viewed. Examples of cervical and colorectal screening are highlighted because they detect precursor lesions, facilitating cancer prevention.

Figure 2 shows a subset, sex-stratified analysis of women aged 50-69 years (the age range during which most are eligible for all 5 tests), and of men aged 50-74 years (the age range during which most are eligible for all 3 tests). Each dot represents the observed rate for one small area. Among all small areas, mean participation in all tests combined among women is $31.6 \%$ (SD $11.0 \%$ ) and among men is $41.2 \%$ (SD $12.0 \%$ ). Calculations were based on all small areas, but only small areas with at least 50 eligible women and 50 eligible men have been plotted. The central tendencies are surprisingly low, given that all eligible people have universal governmentfunded health insurance.

Without overdispersion, the expected count of small areas above and below the 99\% confidence interval (CI) (3 SDs beyond the mean), would have been $0.5 \%$ (473 small areas) each. However, we observe 10.2\% (1932 small areas) are above the 99\% CI, and $11.7 \%$ (2207 small areas) are below the $99 \%$ CI, for women having all 5 tests for which they are eligible, and $12.3 \%$ (2336 small areas) are above the 99\% CI, and $13.8 \%$ (2614 small areas) are below the 99\% CI for men having all 3 tests for which they are eligible. Overdispersion below the lower 99\% CI indicates how infrequently screening is adopted among small areas with deprivation and barriers. Despite overdispersion above the upper 99\% CI for large numbers of small areas, the participation rates even in the "best" served areas are suboptimal.

Figure 3 plots the median screening prevalence of participation, stratified by sex, for each test individually, for any one test, and for all 5 tests for which women aged 50-69 years, and for all 3 tests for which men aged 50-75 years are eligible, by small area. This illustrates the large difference between the percentage with participation in any one eligible test, and the percentage with participation in all eligible tests. Median screening prevalence among small areas, for each test, and for all tests combined stratified by sex, increases with increasing

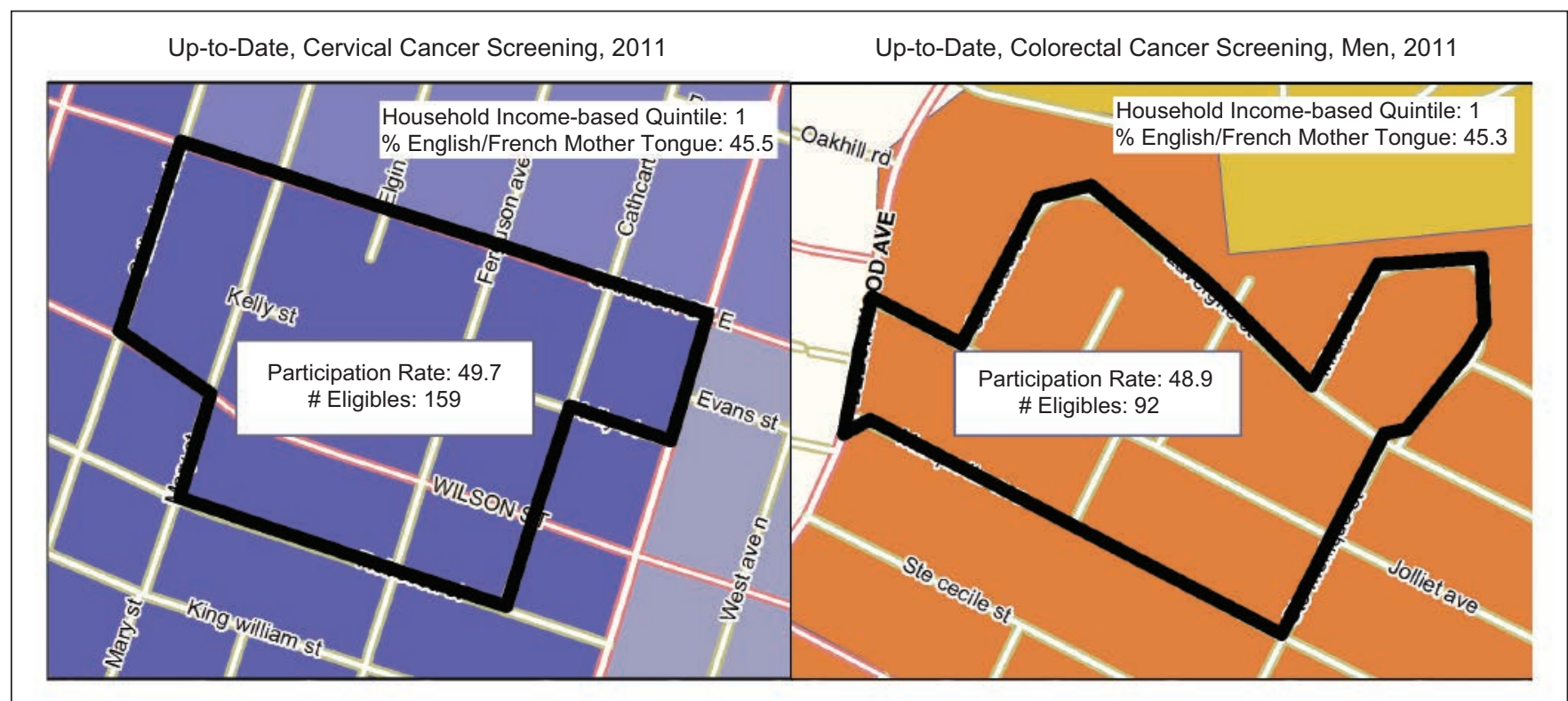

Figure 1: Sample output from the geographic information system. The left figure shows a small area's rate of women up to date on cervical cancer screening in 2011. The right figure shows a different small area's rate of men up to date on colorectal cancer screening in 2011. Both figures also display the small area's household income-based quintile, percentage of residents whose mother tongue is English or French, and percentage of residents who are immigrants. 
percentage of people with high school completion, increasing income quintile, increasing number of primary care visits, and increasing percentage of people with an identifiable physician.

\section{Individual-level results}

In our supplementary materials (Appendix 1), we describe individual participation by screening test stratified by individual-level variables, including physician characteristics, distributed at the individual-level and area-level variables. Table S1 is restricted to those eligible people with an identifiable physician and Table S2 to those without. Figure S1 presents adjusted odds ratios for individual screening tests among those with an identifiable physician and Figure S2 among those without. None of the interaction terms defined a priori substantially changed estimates and hence were not included in the models. The interpretation of individuallevel analysis is consistent with the small-area analysis.

A

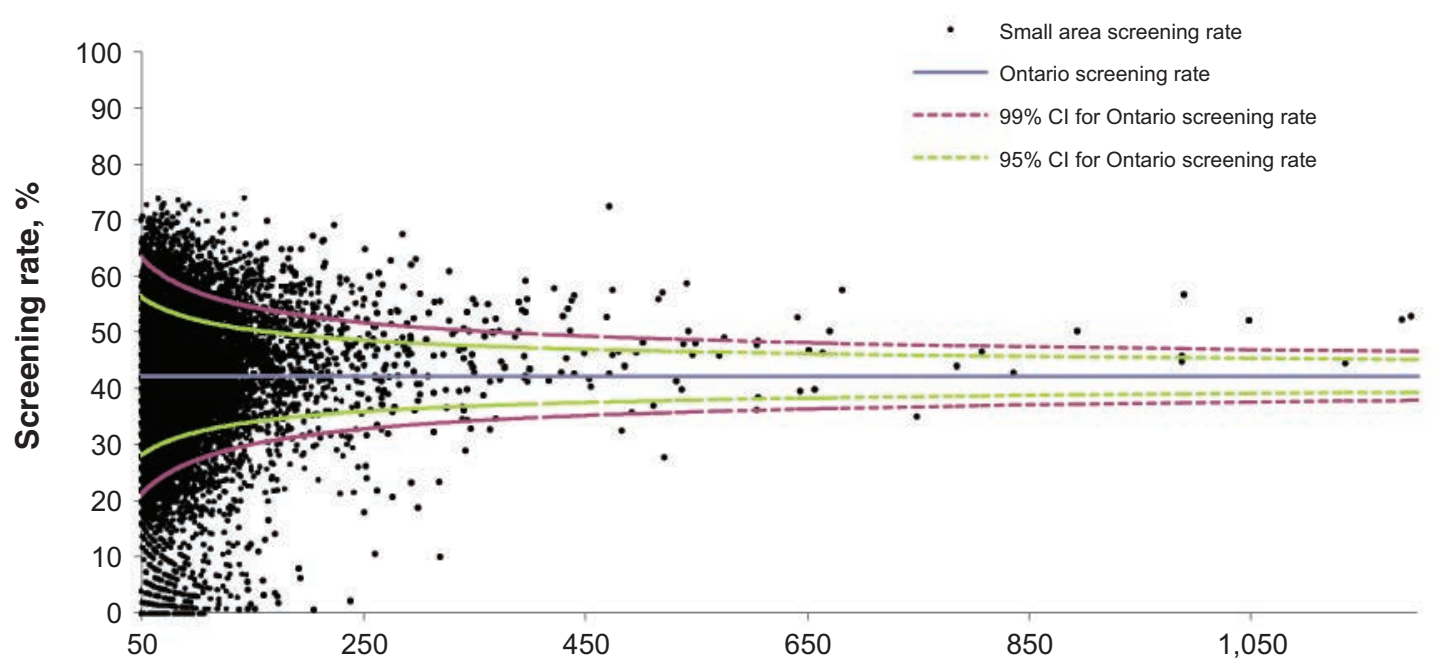

Number of eligible men in small area

B

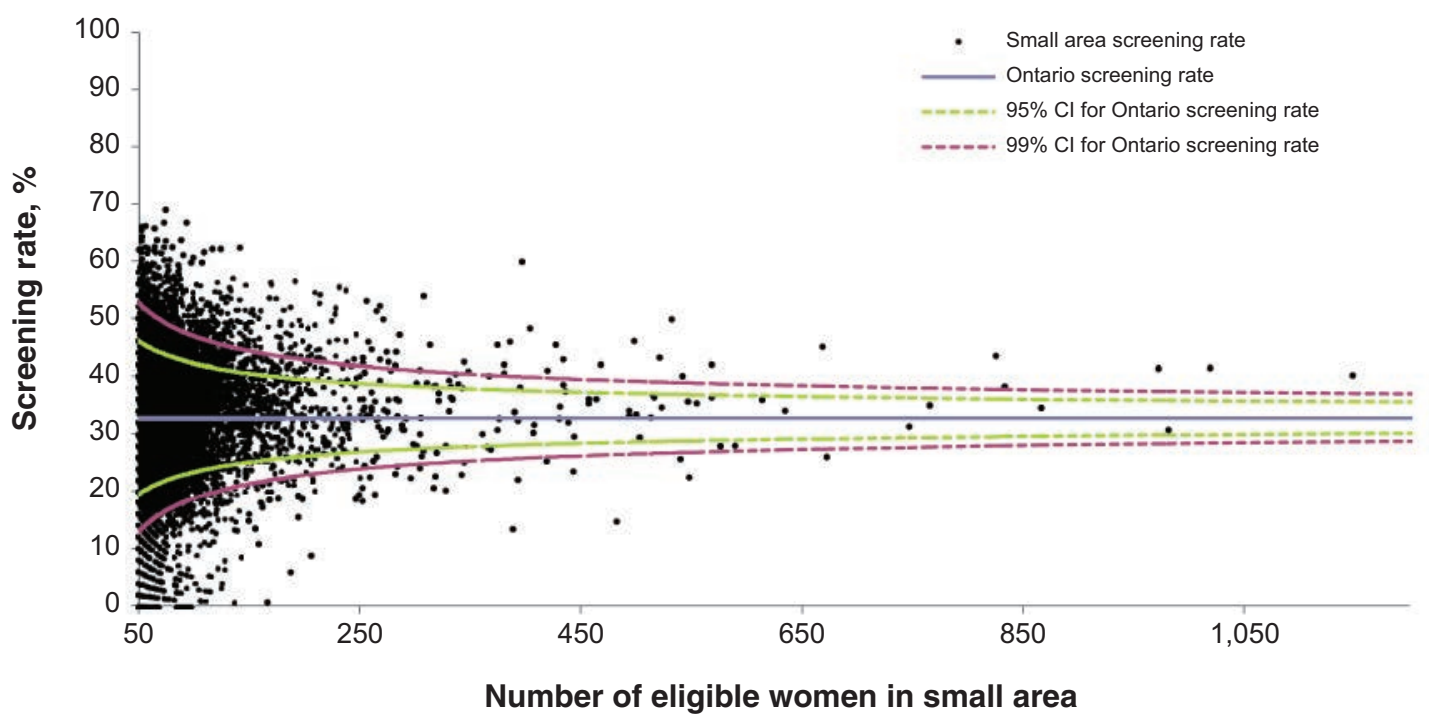

Figure 2: Funnel plots displaying rates of eligible people being up to date on (A) all 5 tests (colorectal, breast, cervical, glucose, cholesterol) for women in 18925 small areas and (B) all 3 tests (colorectal, glucose, cholesterol) for men in 18933 small areas in Ontario. The screening rate for each small area $(\bullet)$ is calculated as the number of eligible people receiving all screening tests divided by the number of people eligible for all tests in the small area. The blue horizontal lines at $32.8 \%(\mathrm{~A})$ and $42.8 \%(\mathrm{~B})$ are the overall screening rates in Ontario for women and men, respectively, calculated as the number of eligible women and men receiving all screening tests divided by the number of women and men eligible for all screening tests in Ontario. 95\% (green lines) and 99\% (red lines) confidence intervals were generated using the asymptotic normal approximation set at 2 and 3 SDs from the overall Ontario screening rates for women and men. Screening rates are displayed for small areas with 50 or more eligible people. 


\section{Interpretation}

The rate of participation in all eligible tests among small areas is much lower than the rate of participation in any one particular test. Rates vary with factors of demographics, deprivation, barriers and primary care, as has been shown repeatedly in several countries. ${ }^{10,11,14-25}$
Current levels of participation have been attained primarily by physician recommendation and promotion of screening programs to individuals. Studies of financial incentives to physicians for screening and primary care reforms between the years 2000 and 2009 have not had an impact on screening participation. ${ }^{6-9}$ There is strong evidence indicating that primary care practices could do better

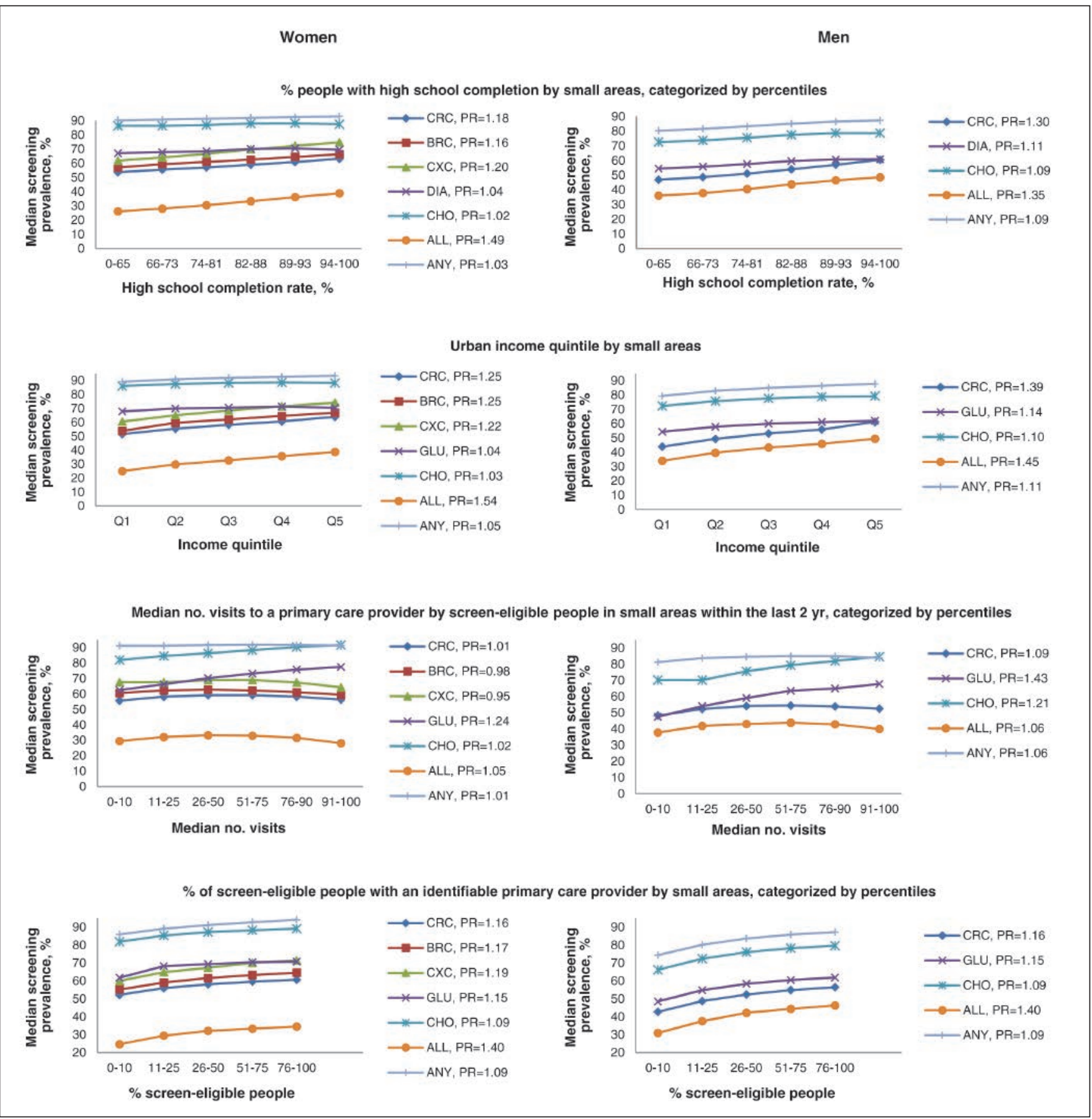

Figure 3: Median screening prevalence for small areas stratified by screening tests and demographic characteristics. $Y$ axis: Median screening prevalence (\%). X axis: small areas stratified by screening tests and demographic characteristics specified in graph title. Prevalence ratios (PRs) are reported as [median screening prevalence of highest stratum/median screening prevalence of lowest stratum]. Note: ALL = median screening prevalence for all tests among people eligible for all tests, ANY = median screening prevalence for any one test among those eligible for all tests, $\mathrm{BRC}=$ breast, $\mathrm{CHO}=$ cholesterol, $\mathrm{CRC}=$ colorectal, $\mathrm{CXC}=$ cervical, $\mathrm{GLU}=$ glucose . 
in encouraging participation among those who actually attend the practices. ${ }^{36-38}$

\section{Limitations}

We did not have data by which to examine the relation of Aboriginal status to small-area screening rates. Although there is no record of screening versus diagnostic intention of any of these tests, people already affected by those cancers, diabetes or myocardial infarction have been excluded from the study population, and the annual incidence of new cases of these diseases is very small compared with the volumes tested. It was beyond the scope of this work to evaluate the follow-up of abnormal screening tests; however, follow-up of abnormal tests might also vary by the same demographic, socioeconomic and primary care factors. ${ }^{10,11,14-25}$

There is no consensus about a benchmark level of participation for individual screening tests or for all tests which are age and sex appropriate. The benchmark would be less than $100 \%$ because individuals might have contraindications to procedures precipitated by an abnormal screening result, and some might decline screening. We did not benchmark the top $10 \%$ of small-area rates for all tests combined in this study, because this sex-stratified rate was only $45 \%$ for women and $55 \%$ for men among small areas with 250 eligible people per sex.

\section{Implications for practice}

In the absence of appropriate benchmarks, we recommend setting a sequence of targets for improving the mean rates among women from $31.6 \%$ to $65 \%$, and among men from $41.2 \%$ to $65 \%$, in a stepwise manner over a 10 -year period or less. This will be difficult to achieve, even though $65 \%$ is not optimal. For individual tests, the screening rates are higher for cholesterol than cancer and glucose; improving participation in cervical and colorectal screening would be very rewarding as those tests detect precursors of cancer, the treatment of which will prevent cancer.

The data shown in this study are composed of personal health information, although aggregate (no counts or percentages reflecting $\leq 5$ people), anonymous and impossible to link to any personal identity. Every rate with more than 5 counts in the numerator is publishable, according to the Information and Privacy Commissioner of Ontario, as long as there is minimal risk of re-identification. There is no privacy and confidentiality barrier for use of the geographic information system containing these data for developing and delivering strategies that intervene at the neighbourhood or community level to improve screening participation in Ontario, especially among small areas with low screening participation and lower average number of primary care visits, and aiming at participation in all tests for which one is eligible.

We suggest community-based and primary care-based strategies should include a focus on small areas (e.g., in areas with lower high school completion, lower average number of primary care visits by any physician) rather than strategies aimed at the generic "average" eligible person, as has been the case. We also suggest that strategies focus not on improving rates for one screening test at a time, but instead on efforts to facilitate participation in all appropriate tests for which a person is eligible.

In addition, we suggest small area-level factors be addressed at the neighbourhood and community level to improve participation by complementing primary care. Lay or professional health visitors canvassing neighbourhoods, locally focused promotional advertising and mobile health vans are a few of a wide range of feasible small-area interventions.

\section{Conclusion}

Our results show that the rate of participation in all eligible screening tests among small areas is much lower than the rate of participation in any one particular test. This finding has implications for the design and implementation of strategies to improve rates of screening.

\section{References}

1. Dickinson J, Tsakonas E, Conner Gorber S, et al.; Canadian Task Force on Preventive Health Care. Recommendations on screening for cervical cancer. CMA7 2013;185:35-45.

2. Tonelli M, Connor Gorber S, Joffres M, et al.; Canadian Task Force on Preventive Health Care. Recommendations on screening for breast cancer in averagerisk women aged 40-74 years. CMA7 2011;183:1991-2001.

3. Canadian Task Force on Preventive Health Care. Colorectal cancer screening: Recommendation statement from the Canadian Task Force on Preventive Health Care. CMA7 2001;165:206-8.

4. Pottie K, Jaramillo A, Lewin G, et al.; Canadian Task Force on Preventive Health Care. Recommendations on screening for type 2 diabetes in adults. CMA7 2012;184:1687-96.

5. Genest J, McPherson R, Frohlich J, et al. 2009 Canadian Cardiovascular Society / Canadian guidelines for the diagnosis and treatment of dyslipidemia and prevention of cardiovascular disease in the adult -2009 recommendations. Can $\mathcal{F}$ Cardiol 2009;25:567-79.

6. Cancer screening: breast, cervial and colorectal. Cancer Quality Council of Ontario. Available: www.csqi.on.ca/comparisons/cancer_screening (accessed 2014 Mar. 31).

7. Screening. Cancer Care Ontario. Available: www.cancercare.on.ca/pcs/screening (accessed 2014 Mar. 31).

8. Kiran T, Wilton AS, Moineddin R, et al. Effect of payment incentives on cancer screening in Ontario primary care. Ann Fam Med 2014;12:317-23.

9. Hutchison B, Glazier R. Ontario's primary care reforms have transformed the local care landscape, but a plan is needed for ongoing improvement. Health Aff (Millwood) 2013;32:695-703.

10. Borkhoff CM, Saskin R, Rabeneck L, et al. Disparities in receipt of screening tests for cancer, diabetes and high cholesterol in Ontario, Canada: a populationbased study using area-based methods. Can f Public Health 2013;104:e284-90.

11. Meijer M, Bloomfield K, Engholm G. Neighbourhoods matter too: the association between neighbourhood socioeconomic position, population density and breast, prostate and lung cancer incidence in Denmark between 2004 and 2008. 7 Epidemiol Community Health 2013;67:6-13.

12. Diehr P, Cain K, Connell F, et al. What is too much variation? The null hypothesis in small-area analysis. Health Serv Res 1990;24:741-71.

13. Spiegelhalter DJ. Funnel plots for comparing institutional performance. Stat Med 2005;24:1185-202.

14. Lofters A, Glazier RH, Agha MM, et al. Inadequacy of cervical cancer screening among urban recent immigrants: a population-based study of physician and laboratory claims in Toronto, Canada. Prev Med 2007;44:536-42.

15. Lofters AK, Moineddin R, Hwang SW, et al. Low rates of cervical cancer screening among urban immigrants: a population-based study in Ontario, Canada. Med Care 2010;48:611-8.

16. Lofters AK, Moineddin R, Hwang SW, et al. Predictors of low cervical cancer screening among immigrant women in Ontario, Canada. BMC Womens Health 2011;11:20.

17. Elit L, Krzyzanowska M, Saskin R, et al. Sociodemographic factors associated with cervical cancer screening and follow-up of abnormal results. Can Fam Physician 2012;58:e22-31.

18. Lofters AK, Gozdyra P, Lobb R. Using geographic methods to inform cancer screening interventions for South Asians in Ontario, Canada. BMC Public Health 2013;13:395.

19. Honein-AbouHaidar GN, Baxter NN, Moineddin R, et al. Trends and inequities in colorectal cancer screening participation in Ontario, Canada, 20052011. Cancer Epidemiol 2013;37:946-56.

20. Katz SJ, Hofer TP. Socioeconomic disparities in preventive care persist despite 
universal coverage. Breast and cervical cancer screening in Ontario and the United States. 7AMA 1994;272:530-4.

21. Katz SJ, Zemencuk JK, Hofer TP. Breast cancer screening in the United States and Canada, 1994: socioeconomic gradients persist. Am 7 Public Health 2000; 90:799-803.

22. Singh SM, Paszat LF, Li C, et al. Association of socioeconomic status and receipt of colorectal cancer investigations: a population-based retrospective cohort study. CMA7 2004:171:461-5.

23. Wilson SE, Rosella LC, Lipscombe LL, et al. The effectiveness and efficiency of diabetes screening in Ontario, Canada: a population-based cohort study. BMC Public Health 2010;10:506.

24. Creatore MI, Booth GL, Manuel DG, et al. Diabetes screening among immigrants: a population-based urban cohort study. Diabetes Care 2012;35:754-61

25. Siddiqi A, Zuberi D, Nguyen QC. The role of health insurance in explaining immigrant versus non-immigrant disparities in access to health care: comparing the United States to Canada. Soc Sci Med 2009;69:1452-9.

26. Leddin DJ, Enns R, Hilsden R, et al. Canadian Association of Gastroenterology position statement on screening individuals at average risk for developing colorectal cancer: 2010. Can 7 Gastroenterol 2010:24;705-14.

27. Tonelli M, Connor Gorber S, Joffres M, et al.; Canadian Task Force on Preventive Health Care. Recommendations on screening for breast cancer in average-risk women aged 40-74 years. CMA7 2011;183:1991-2001.

28. Murphy J, Kennedy EB, Dunn S, et al. Cervical screening: a guideline for clinical practice in Ontario. 7 Obstet Gynaecol Can 2012;34:453-8.

29. Pottie K, Jaramillo A, Lewin G, et al.; Canadian Task Force on Preventive Health Care. Recommendations on screening for type 2 diabetes in adults. CMA7 2012;184:1687-96.

30. Genest J, McPherson R, Frohlich J, et al. 2009 Canadian Cardiovascular Society/ Canadian guidelines for the diagnosis and treatment of dyslipidemia and prevention of cardiovascular disease in the adult-2009 recommendations. Can 7 Cardiol 2009;25:567-79.

31. Holowaty EJ, Norwood TA, Wanigaratne S, et al. Feasibility and utility of mapping disease risk at the neighbourhood level within a Canadian public health unit: an ecological study. Int 7 Health Geogr 2010;9:21.

32. Davison AC, Hinkley DV. Bootstrap methods and their application. 1st ed. Cambridge: Cambridge university Press; 1997.

33. Hanley JA, Negassa A, Edwardes M, et al. Statistical analysis of correlated data using generalized estimating equations: an orientation. Am 7 Epidemiol 2003; 157:364-75.

34. Kutner MH, Nachtsheim CJ, Neter J. Applied linear regression models. 4th ed. Chicago: McGraw-Hill Irwin, 2004.

35. Harrell FE. Regression modeling strategies: with applications to linear models, logistic regression, and survival analysis. New York: Springer-Verlag New York; 2001

36. Grunfeld E, Manca D, Moineddin R, et al.; BETTER Trial Investigators.
Improving chronic disease prevention and screening in primary care: results of the BETTER pragmatic cluster randomized controlled trial. BMC Fam Pract $2013 ; 14: 175$.

37. Campbell-Scherer D, Rogers J, Manca D, et al. Guideline harmonization and implementation plan for the BETTER trial: Building on Existing Tools to Improve Chronic Disease Prevention and Screening in Family Practice. CMAJ Open 2014;2:E1-E10.

38. Manca DP, Aubrey-Bassler K, Kandola K, et al. Implementing and evaluating a program to facilitate chronic disease prevention and screening in primary care: a mixed methods program evaluation. Implement Sci 2014;9:135.

Affiliations: Institute for Clinical Evaluative Sciences (Fernandes, Sutradhar, Borkhoff, Baxter, Lofters, Rabeneck, Tinmouth, Paszat); Dalla Lana School of Public Health (Sutradhar, Borkhoff, Rabeneck, Paszat); St. Michael's Hospital (Baxter, Lofters); Institute of Health Policy, Management and Evaluation (Borkhoff, Baxter, Lofters, Rabeneck, Tinmouth, Paszat); University of Toronto (Sutradhar, Borkhoff, Baxter, Lofters, Rabeneck, Tinmouth, Paszat); Cancer Care Ontario (Rabeneck); Sunnybrook Health Sciences Centre (Tinmouth), Toronto, Ont.

Contributors: All authors contributed to the conception and design of the study, and interpreted the data. Kimberly Fernandes led the analysis. Kimberly Fernandes and Lawrence Paszat drafted the article. All authors revised the manuscript for important intellectual content, approved the final version to be published and agreed to act as guarantors of the work.

Disclaimer: This study was supported by the Institute for Clinical Evaluative Sciences (ICES) which is funded by an annual grant from the Ontario Ministry of Health and Long-Term Care (MOHLTC). The opinions, results and conclusions reported in this article are those of the authors and are independent from the funding sources. No endorsement by ICES or the Ontario MOHLTC is intended or should be inferred.

Acknowledgement: Parts of this material are based on data and information compiled and provided by the Canadian Institute for Health Information (CIHI). However, the analyses, conclusions, opinions and statements expressed herein are those of the authors, and not necessarily those of CIHI.

Supplemental information: For reviewer comments and the original submission of this manuscript, please see www.cmajopen.ca/content/3/4/ E373/suppl/DC1 